\title{
Los principios del Derecho global de la contratación pública
}

The principles of global procurement

\author{
JAIME RODRÍGUEZ-ARANA*
}

Resumen: El siguiente texto analiza los efectos de la globalización en el Derecho Público, especialmente en la contratación pública. En este marco el artículo nos introduce al estudio del Derecho Administrativo Global como un nuevo campo en desarrollo que adolece todavía de legitimidad debido, entre otros factores a la ausencia de un órgano legislativo global. Finalmente, se analizan las principales dificultades acerca del establecimiento de principios sobre los que levantar el edificio del Derecho Administrativo Global y los avances que, sobre la materia, se han desarrollado en la Unión Europea.

Palabras clave: Derecho administrativo global - principios generales - contratación pública

Abstract: The following article examines the effects of globalization on public law, especially in public procurement. In this context, the article introduces the study of GAL as a new developing field still lacks legitimacy because, among other factors in the absence of a global legislative body. Finally, it analyzes the main difficulties concerning the establishment of principles on which the building up of GAL and progress on the subject has been developed in the European Union.

Key words: Global administrative law - general principles - government procurement

CONTENIDO: I. EL DERECHO ADMINISTRATIVO GLOBAL.- II. LOS PRINCIPIOS

GENERALES Y EL DERECHO ADMINISTRATIVO GLOBAL.- III. LOS PRINCIPIOS GENERALES DE LA CONTRATACIÓN PÚBLICA EN EL DERECHO ADMINISTRATIVO GLOBAL.- IV. REFLEXIÓN CONCLUSIVA.

\section{INTRODUCCIÓN}

La globalización es un fenómeno que también ha llegado al Derecho público. En efecto, la realidad nos demuestra que en determinados sectores del Derecho administrativo existen normas y actos con pretensión de validez supranacional. Son normas que se elaboran al poner en cuestión la teoría clásica de las fuentes del Derecho y el sistema de producción normativa. Como el Derecho administrativo global está in fieri, este es,

Presidente del Foro Iberoamericano de Derecho administrativo y catedrático de Derecho administrativo en la Universidad de La Coruña. 
en mi opinión, un Derecho principial. Un Derecho en construcción, que asegura que los poderes públicos globales se ejercen al servicio del interés general global y de acuerdo con la justicia. Ni hay todavía una administración pública global, ni un poder ejecutivo global, ni un poder judicial global, así como tampoco disponemos de una constitución global. Sin embargo, la realidad nos demuestra que en algunos sectores —el de la contratación pública especialmente- los principios generales ayudan sobremanera a construir un Derecho administrativo global de la contratación administrativa que parta precisamente de los postulados del Estado de Derecho.

La ausencia, en ocasiones, de legitimidad de estas nuevas fuentes del Derecho - a veces compuestas por grupos de expertos, por especialistas en determinadas materias que se reúnen a nivel global, o también por tradicionales entes públicos, semipúblicos, e incluso en ocasiones conformadas por entes privados- hace preciso que en estos primeros tiempos el levantamiento del nuevo edificio jurídico-administrativo se realice sobre bases sólidas. En materia de contratos, son los entes públicos supranacionales o globales quienes, a partir de la objetividad, transparencia, igualdad de trato y prohibición de discriminación por razón de nacionalidad, han construido un ordenamiento jurídico comunitario europeo que, por mor de las características de la integración comunitaria europea, obliga a los Estados miembros.

En esta intervención me propongo reflexionar sobre un fenómeno de rabiosa y palpitante actualidad como es el del Derecho administrativo global analizando un sector concreto: la contratación pública. Un sector al cual, efectivamente, el Derecho que lo disciplina es de contenido prudencial y consecuencia de la fuerza de la integración; en este caso, de la integración comunitaria. Además, y es importante destacarlo, los principios generales que presiden el régimen de la contratación pública en Europa surgen de la metodología del pensamiento abierto, dinámico y complementario. En este sentido, los principios que vamos a analizar comparten la misma base que un fenómeno de integración en el que la libertad, la competencia, la igualdad de trato, la no discriminación, la transparencia, la imparcialidad y la objetividad presiden el entero sistema normativo de la contratación administrativa en el seno de la UE.

\section{EL DERECHO ADMINISTRATIVO GLOBAL}

La existencia del Derecho administrativo global es, a día de hoy, una realidad indudable. Poco a poco va inundando los sectores tradicionales del Derecho administrativo interno o nacional. Esto es así, entre otras razones, porque las categorías y las instituciones del Derecho administrativo no están limitadas a unas determinadas y concretas coordenadas espacio-temporales. Más bien, se trata de categorías y conceptos de validez 
universal que podrían tener un sentido o una intensidad diferente según cual sea el modelo de Estado en el que nos encontremos. Por ejemplo, los contratos públicos, aquellos que celebran los entes del sector público en su fisonomía general y en su articulación concreta, suelen presentar unos obvios rasgos comunes que justamente demuestran la existencia de esta categoría jurídico-administrativa desde su nacimiento.

Los entes públicos, por utilizar una terminología muy amplia en la que entran todas las administraciones públicas y entes dependientes, además de sociedades y otros organismos que manejan fondos públicos, suelen convocar a las empresas, mediante publicidad y concurrencia, para realizar actividades de interés general, actividades que la propia institución solicitante ni está en condiciones de realizar por sí misma, ni probablemente deba hacerlo. La Unión Europea, el Mercosur, las Naciones Unidas, el Banco Mundial, el Fondo Monetario Internacional, el Banco Interamericano de Desarrollo y otros órganos y organismos de dimensión supranacional contratan a empresas para la realización de terminadas obras o servicios públicos; siguen para ello una tipología que, aunque ha nacido en el Derecho administrativo interno, hoy es una realidad en el denominado Derecho administrativo global de la contratación pública.

El problema que hoy presenta este Derecho administrativo global es que es un Derecho in fieri que se está desarrollando poco a poco, que adolece todavía de una inquietante ausencia de legitimidad debida a la inexistencia de un parlamento global, de un gobierno global y de un tribunal global. Por eso, este incipiente Derecho público global opera, como es lógico, a través de principios que proyectan la cláusula del Estado de Derecho, en un intento de evitar que la racionalidad económica o la racionalidad técnica terminen por convertirse en la fuente primera y más relevante de este ordenamiento jurídico-administrativo global.

En este punto, el caso de la contratación pública es paradigmático, puesto que, como se analiza en esta intervención - pionera ciertamente en la materia en lo que a lengua hispana se refiere-, los principales instrumentos supranacionales y globales en materia de contratación se han construido precisamente al calor de los principios: los de no discriminación, de publicidad, de libre concurrencia, etcétera. Estos principios son la expresión de la obligatoriedad que tienen los entes públicos - al manejar fondos públicos- de actuar con transparencia, de fomentar la igualdad y adjudicar el contrato a la mejor oferta con miras al interés público, que es siempre el elemento central que gravita y preside el entero régimen jurídico de aplicación. Es decir, en materia de contratos públicos, los principios han sido la base de las normas que ulteriormente se han elaborado. En el espacio jurídico europeo, por ejemplo, el caso de las directivas comunitarias en la materia nos excusa ahora de mayores comentarios. 
A pesar de registrar que el Derecho administrativo global no ha cumplido hasta el momento el papel que se esperaba de él —ordenación jurídica del poder para la libertad de todos los seres humanos en la dimensión global-, no se puede desconocer que en la realidad jurídica general del espacio jurídico global se han producido, quizá demasiado tímidamente y probablemente demasiado lentamente, toda una serie de hechos y regulaciones que - aunque sea fragmentariamente- acreditan la existencia de una parcial regulación administrativa de escala supranacional. Sin embargo, en el ámbito de la contratación pública es donde, a mi juicio, el desarrollo del Derecho administrativo global ofrece más solvencia, precisamente a causa de haberse diseñado sobre los cimientos de los principios tradicionales de la contratación pública, que son prácticamente comunes en casi todos los ordenamientos del planeta y se encuentran inspirados en el derecho de matriz romano-germánica.

El fenómeno de la globalización, imparable en el terreno económico, hoy ya alcanza y llega a todas las ciencias sociales sin excepción. En lo que se refiere al Derecho público, comprobamos con frecuencia la existencia de sectores de la denominada actividad administrativa —en sentido amplio- que están trufados de regulaciones transnacionales o, por mejor decir, transgubernamentales, que obligan al estudioso del Derecho administrativo a no perder de vista esta nueva realidad. Es el caso, entre otros, de la seguridad pública, de la regulación de la energía, de las telecomunicaciones, de la inmigración, del medio ambiente, de la llamada ayuda al desarrollo y, muy especialmente, de la contratación pública.

Esto es así, entre otras razones, porque hoy la interdependencia y la cooperación intergubernamental nos enseñan que la solución a muchos problemas de dimensión pública ha de buscarse a través de esta nueva versión del pensamiento abierto, plural, dinámico y complementario que se llama globalización.

Este nuevo panorama afecta sobremanera a los principios sobre los que descansa el Derecho administrativo. Es verdad que en nuestra disciplina coexisten dos tradiciones jurídicas que son afectadas por la globalización actualmente. Más, desde luego, el sistema jurídico-administrativo de corte francés que el esquema del rule of law de inspiración anglosajona. Pero, en cualquier caso, ambos sistemas tienen que aggiomarse a la nueva realidad. Es más: en sede de principios, los fundamentos del Estado de Derecho, aquellos sobre los que se han levantado ambos edificios jurídicos, cobran ahora una especial relevancia, puesto que no podemos ocultar que estas nuevas formas de actividad pública de dimensión global no pueden ni deben escapar al control jurídico que legitima la acción pública. En el ejercicio de estos poderes regulatorios que tienen diferentes protagonistas - incluso de naturaleza privada - deben asegurarse técnicas que impidan que la tentación de eludir el control sea la 
principal característica de la denominada "nueva administración global" que despliega su actividad en el llamado espacio jurídico global.

Por eso, en los inicios, en los primeros balbuceos de este todavía incipiente Derecho administrativo global, la jurisprudencia, y sobre todo los principios del Derecho sobre los que se levantó esta magnífica construcción jurídico-política, están fundando un nuevo Derecho público universal que, como señala agudamente el profesor Meilán, es ya un Derecho prudencial. Acontece, mutatis mutandis, lo mismo que en los orígenes del Derecho administrativo en Francia. En ese entonces fue el Consejo del Estado el que alumbró el nuevo Derecho administrativo a través de sus famosos arrets; ahora son los tribunales y las cortes sectoriales de nivel transgubernamental o global los que poco a poco van elaborando una doctrina jurisprudencial que, hoy como ayer, se basan en principios de Derecho.

Como es sabido, mientras que en el sistema continental europeo el control de la actividad administrativa se ubicó en manos del Consejo de Estado - un organismo público de naturaleza jurisdiccional- y dado que la administración pública actúa sometida a un derecho diferente al común para las personas jurídicas ordinarias - repleto de privilegios y prerrogativas en cuanto servidora del interés general-, en la otra orilla, nunca mejor escrito, la administración era considerada como una persona jurídica más sometida al Derecho que interpretan los tribunales ordinarios. En ambos casos, como es lógico, la administración estaba sometida a la ley y al Derecho.

En el Derecho administrativo anglosajón, poco a poco, se empezaron a aplicar a los contratos públicos, reglas propias de un sistema que asume que la existencia de fondos públicos obliga a disponer de un régimen jurídico adecuado a tal característica. Los contratos privados se rigen por la ley de la autonomía de la voluntad con los límites propios establecidos en los códigos correspondientes, mientras que los contratos públicos, por la existencia de fondos públicos, están sometidos a los principios de publicidad, objetividad, equidad, concurrencia, igualdad de trato y transparencia. Principios hoy de aplicación — por mor de la fuerza del Derecho público comunitario europeo- a todos los países de la Unión Europea, sean de tradición anglosajona o francesa.

En este contexto, las experiencias de Derecho administrativo global en distintos sectores, como puede ser el de los derechos humanos, el del comercio internacional, el cultural, el agrícola, el de la contratación pública, el deportivo, entre otros — todos ellos de dimensión universal-, van a mostrarnos un conjunto de resoluciones de naturaleza judicial, y unas normas y prácticas administrativas que, desde luego, superan las fronteras nacionales. En efecto, desde el principio de legalidad hasta la separación de los poderes, pasando por la primacía de

LOS PRINCIPIOS DEL DERECHO GLOBAL DE LA CONTRATACIÓN PÚBLICA

THE PRINCIPLES OF GLOBAL PROCUREMENT 
los derechos fundamentales de las personas y sin perder de vista la relevancia del pluralismo, de la racionalidad, de la transparencia, del buen gobierno, de la rendición de cuentas, así como de la instauración de un efectivo sistema de checks and balances, encontramos principios y criterios del Estado de Derecho que nos permiten hablar de un Derecho administrativo global de base principial. Base principial, insisto, que en materia de contratos es patente.

Ciertamente, uno de los peligros que se avizoran cuando nos acercamos al estudio de la administración global, del espacio jurídico-administrativo global y, sobre todo, cuando estudiamos el Derecho administrativo global es la facilidad con la que estas nuevas realidades jurídicas y estructurales pueden escapar al control, al sistema de accountability o de rendición de cuentas que debe caracterizar a una verdadera y genuina administración democrática. Por eso, ahora que percibimos la emergencia de este nuevo Derecho administrativo en el que existe, todavía in fieri, una nueva administración global que opera en el nuevo espacio jurídico global, es fundamental desde ya que los principios sobre los que va a descansar esta nueva realidad jurídico-pública se inscriban claramente en los postulados del Estado de Derecho.

En materia de contratación pública, nos topamos con un problema complejo, dado que en el espacio europeo resulta que el principio de igualdad de trato es desconocido muchas veces a favor de las empresas nacionales por diferentes "razones": desde la promoción de la industria nacional hasta la protección de la economía propia.

En este sentido, los profesores Kingsbury, Krisch y Stewart son conscientes de que puede haber determinadas regulaciones globales que pueden afectar de manera distinta a unos Estados y a otros, y cuestionan incluso el régimen del Derecho internacional público. Para resolver este escollo, los profesores abogan porque los regímenes intergubernamentales construyan estándares de Derecho administrativo y técnicas jurídicas generales a las que los gobiernos nacionales deban adecuarse con el fin de asegurar que los principios del Estado de Derecho sean respetados. En materia de contratación, los principios son la clave de bóveda del sector. Sin principios, que además son globales, no hay sistema global de contratación pública global.

Es verdad que ahora se pone el acento en la rendición de cuentas, en la transparencia, en la racionalidad, en la evaluación, en la legalidad y, entre otros paradigmas, en la participación. Estos son los nuevos principios que ahora están de moda en los estudios de Derecho administrativo global. Ahora bien, al ser muy importante que las formas de producción de actos administrativos y de normas de la administración global estén inspirados en el primado de estos principios, no podemos olvidar que el Estado de Derecho trae consigo, además, como conquista irrenunciable, 
la centralidad de los derechos fundamentales de las personas y el equilibrio y la separación entre los poderes. Si en el estudio de los principios solo atendemos a criterios de eficacia o de eficiencia y nos olvidamos de la manera en que el poder administrativo global incide en la mejora de las condiciones de vida de la ciudadanía, podríamos caer en una perspectiva puramente funcionalista del Derecho administrativo global.

En alguna medida, la crisis de la regulación en relación con la actividad financiera a nivel nacional en algunos estados pone de manifiesto la importancia de una regulación global que pueda atender y realizar su papel ante fenómenos que en sí mismos son globales, tales como el sistema financiero y la economía. El control de la economía por el Derecho administrativo no es más que la garantía necesaria para que los agentes trabajen en un clima de confianza que demuestre que el sistema de mercado se mueve en un marco de racionalidad y equilibrio. En materia de contratación con fondos públicos, la relación entre Derecho y economía es obvia, por lo que en estos casos la racionalidad técnica ha de integrarse en el marco de los postulados del Estado de Derecho, lugar donde nacen los principios de igualdad, transparencia, publicidad, objetividad, imparcialidad, interés público, entre otros. La cuestión, pues, se va a centrar en proyectar toda la fuerza del Estado de Derecho sobre el Derecho administrativo global sin olvidar que, efectivamente, hoy la acción administrativa, precisamente por la fuerza del Estado de Derecho, ha de expresarse en términos de transparencia, participación, responsabilidad, racionalidad y permanente evaluación.

El Derecho administrativo global existe porque hay una acción administrativa global. Y hay una acción administrativa porque se han ido conformando en este tiempo un conjunto de estructuras de regulación global —no siempre de composición estrictamente pública— que han producido actos y normas proyectados en un espacio de orden administrativo que llamamos global. Los profesores Kingsbury, Krisch y Stewart dicen que este espacio administrativo global es de orden polifacético, pues en él actúan, como sujetos productores de regulación, instituciones administrativas clásicas, estructuras como ONG o personas jurídicas empresariales que adquieren relevancia administrativa en la medida que dictan reglas de relevancia pública.

Esta realidad, insisto, permite pensar de nuevo en las posibilidades de la concepción objetiva o material del Derecho administrativo y en la capitalidad de la acción administrativa como eje central del concepto mismo de nuestra disciplina. En materia de contratación nos encontramos con los acuerdos de contratación pública de la OMC, con la denominada Ley Modelo de Contratación Pública de Naciones Unidas, con las normas de contratación pública del Tratado de Libre Comercio de América del Norte, con el grupo de trabajo sobre compras del sector público del 
Área de Libre Comercio de las Américas, con el protocolo sobre contrataciones públicas de Mercosur, con las directivas de la Unión Europea en materia de contratación pública, con los acuerdos y tratados celebrados por la Unión Europea con Chile y México y sus previsiones en materia de contratación, con las normas sobre compras del sector público en el marco del Tratado de Libre Comercio entre la Unión Europea y México, así como con otros acuerdos y tratados rubricados por la Unión Europea.

Ciertamente, esta cuestión es polémica puesto que no toda la doctrina ni mucho menos admite que pueda haber regulación administrativa emanada más allá de órganos o estructuras que no sean formalmente administrativas del nivel estatal o nacional, regional o subestatal. Sin embargo, la realidad nos muestra que en el ámbito supranacional existen órganos como la OCDE, el FMI, el Comité de Basilea, el Grupo de Acción Financiera Internacional o la OMC, por ejemplo, que en muy poco tiempo han establecido regímenes regulatorios de naturaleza administrativa con trascendencia y repercusión jurídica a nivel supranacional.

En el ámbito ambiental, sin duda uno de los más representativos del Derecho administrativo global, se puede decir que al día de hoy existe una normativa administrativa global confeccionada, en muchos casos, por estructuras y organizaciones nacidas al calor de las grandes declaraciones mundiales sobre materias como el comercio de emisiones o el desarrollo limpio derivado del Protocolo de Kioto. En el área de la contratación, la clave para saber si estamos ante Derecho administrativo global está en la existencia o no de fondos de relevancia pública, bien sea porque son fondos de instituciones públicas, bien porque se trate de fondos asignados a finalidades de relevancia pública.

Otra de las características que me interesa destacar en este trabajo sobre los principios del Derecho administrativo global aplicados a la contratación pública se refiere a que en la realidad, sin que su nacimiento se haya debido a una sistematización previa, nos encontramos ante acción administrativa global y ante entes públicos, público-privados, incluso privados, que realizan tareas regulatorias de servicio objetivo al interés general. La realidad, que es tozuda, o testaruda, podríamos decir en una expresión quizá no muy científica, demuestra que en el llamado espacio jurídico-administrativo global habita toda una serie de regulaciones de este carácter que están afectando sobremanera al tradicional entendimiento del Derecho administrativo. Por ello, ahora, cuando explicamos en las facultades universitarias Derecho administrativo, tenemos que introducir a los alumnos en el Derecho administrativo global, sobre todo en materia de Derecho regulatorio y en los contenidos de algunos sectores del Derecho administrativo, como pueden ser, por ejemplo, el Derecho ambiental, el Derecho de la contratación pública, el Derecho de la seguridad o el Derecho marítimo. 
La europeización del Derecho administrativo es hoy una realidad. Una realidad que, sin embargo, no está del todo asumida en el interior de los Estados miembros ni interiorizada por numerosos operadores jurídicos de los estados de la Unión Europea. Una de las razones de tal situación se encuentra, efectivamente, en las resistencias mostrencas a la compartición de espacios de soberanía con la unión por parte de los Estados, y por un emergente nacionalismo que impide que el espacio jurídico global sea la realidad que debiera tras tantos años de andadura comunitaria. En cualquier caso, se trata de un proceso jurídico imparable que, con luces y sombras, poco a poco va calando en la conciencia jurídica europea.

La europeización del Derecho administrativo es un proceso que se produce a golpe de reglamento y directiva y así, en la medida en que ambas fuentes del Derecho son de aplicación obligatoria en los Estados miembros de la unión, el Derecho administrativo comunitario siéndose hace más conocido y también más utilizado por los tribunales de justicia de los países miembros. Estas normas jurídicas han venido disciplinando la acción sectorial de la administración, esfera de actuación de la administración europea que contiene las principales políticas públicas de la unión: agricultura, pesca, seguridad, política social, entre otras. En materia de contratación, a pesar de la claridad de las directivas, no se puede ocultar que el principio de igualdad de trato sigue siendo una quimera ante el proteccionismo existente en determinados sectores y frente a la preferencia de las empresas nacionales para la adjudicación de contratos públicos de cierta relevancia. En cambio, cuando se trata de la UE - no de los Estados miembros-, quien protagoniza el proceso de selección de los contratistas, los principios del Derecho europeo de la contratación pública se aplican sin mayores problemas.

\section{II.LOS PRINCIPIOS GENERALES Y EL DERECHO ADMINISTRATIVO GLOBAL}

El Derecho administrativo global es un Derecho principial que al día de hoy progresa a partir de principios de Derecho que, además de proporcionar los criterios generales para construir las instituciones y categorías jurídico-administrativas, garantizan que los postulados del Estado de Derecho iluminen esta nueva realidad. En realidad, en el Derecho administrativo los principios siempre han sido fundamentales, probablemente porque al ser un Derecho relativamente reciente - al menos en su conformación científica - estos han servido de guía para su construcción y desarrollo.

En efecto, la consideración de los principios generales del Derecho en el campo del Derecho administrativo puede realizarse de muy diferentes formas, atendiendo a distintos puntos de vista. Se puede, por ejemplo,

LOS PRINCIPIOS DEL DERECHO

GLOBAL DE LA CONTRATACIÓN PÚBLICA

THE PRINCIPLES OF GLOBAL PROCUREMENT 
analizar su condición de fuente del Derecho y explicar cuáles son sus peculiaridades proyectadas sobre nuestra disciplina. Se puede, también, estudiar específicamente su carácter de elemento informador y transversal de todo el ordenamiento jurídico-administrativo. Igualmente, se puede poner el acento en su conexión con la dimensión ética y en su proyección sobre el plano de los valores. Es posible detenerse a partir del análisis de los principios políticos que presiden el Estado social y democrático de Derecho o centrarse en el estudio de los aforismos, de las técnicas de argumentación, de las reglas de interpretación o de determinados criterios procesales. Es decir, como señala Santamaría Pastor, existe una pluralidad de significados y de aproximaciones en relación con los principios generales que hacen necesario clarificar y concretar el objeto de la reflexión.

El sometimiento del poder público global al Derecho en buena medida se produce gracias a la existencia de una serie de principios que proyectan su luz para ver los problemas en su real y justa dimensión, y que son la atmósfera en la que ha de respirar el ordenamiento jurídico administrativo global. La jurisprudencia de algunos tribunales nacionales y de algunos tribunales del orden global, por ejemplo el tribunal de la OMC, enseña que los principios generales son el resultado del genio jurídico de la construcción del Estado de Derecho y la esencia del entero ordenamiento jurídico.

En el marco del Derecho administrativo, los principios generales son los criterios inspiradores del entero sistema normativo de nuestra disciplina. De este modo, los principios generales — que son la esencia del ordenamiento - siempre nos ayudarán a realizar esa fundamental tarea de asegurar y garantizar que el poder público en todo momento se mueve y actúa en el marco del Derecho. Es más, su carácter inspirador del ordenamiento nos lleva a reconocer en los principios las guías, los faros, los puntos de referencia necesarios para que, en efecto, el Derecho administrativo no se convierta en una maquinaria normativa al servicio del poder de turno sin más asideros que las normas escritas y las costumbres que puedan ser de aplicación en su defecto.

En el caso del Derecho de la contratación pública global, los principios - como ya hemos señalado - juegan un papel central para la existencia de este sector del Derecho administrativo global. Son principios que, como los de objetividad, racionalidad e igualdad de trato, suponen que el Derecho administrativo global cumpla la función que tiene encomendada: la ordenación racional de los asuntos públicos de dimensión global de acuerdo con la justicia.

En los inicios del siglo XXI, la pregunta acerca de la significación de los principios generales del Derecho en el Derecho administrativo puede ser contestada desde dos planteamientos muy distintos. Desde 
el positivismo se diría que los principios generales no tienen apenas más sentido que, en todo caso, el de reconocer en términos abstractos las reglas que se expresan en el sistema normativo. El sistema normativo se brinda a sí mismo los principios porque es el ordenamiento el origen y la causa de ellos. Si, por el contrario, nos situamos en una perspectiva de positivismo abierto, de positivismo que reconoce la existencia de un solar jurídico general, de una cultura jurídica universal y global, podemos afirmar, entonces, que representa el Estado de Derecho, y ahí las cosas son de otra manera.

Desde esta perspectiva, los principios generales juegan un papel central porque son los garantes de que el Estado de Derecho y sus postulados sean una realidad en todas las ramas del Derecho. De esta manera, los principios no son solo fuente del Derecho administrativo global —que no es poco-, sino también elementos inspiradores, criterios sobre los que se debe edificar el Derecho administrativo. Claro, si el Derecho administrativo no es más que una rama del Derecho público que regula las relaciones entre la administración y los ciudadanos sin más, los principios tendrán una funcionalidad muy limitada. Si el Derecho administrativo se concibe — siguiendo a González Navarro 1 — como el Derecho del poder público para la libertad del ser humano, entonces se comprende fácilmente la virtualidad operativa que tienen sus principios en el orden jurídico-administrativo global.

En el caso de la contratación pública global, los principios generales han permitido la elaboración de normas de orden mundial que han establecido el régimen de los contratos de numerosos entes de la denominada "administración pública global". Estos principios permiten en todo momento conocer si las licitaciones se realizan en el marco del Estado de Derecho. O, lo que es lo mismo, si las licitaciones se conducen con arreglo al interés público global, al poner a disposición de los ciudadanos del mundo obras y servicios públicos de calidad que permitan la mejora real de sus condiciones de vida.

A este propósito, debe tenerse presente que el Tribunal Supremo español señaló por sentencia de 18 de febrero de 1992 que:

[...] los principios generales del Derecho, esencia del ordenamiento jurídico, son la atmósfera en que se desarrolla la vida jurídica, el oxígeno que respiran las normas, lo que explica que tales principios informen las normas —art. 1.4 del Código Civil—y que la Administración esté sometida no sólo a la ley sino también al Derecho — art. 103 de la Constitución-. Y es claro que si estos principios inspiran la norma

1 González Navarro, Francisco, Tratado de Derecho Administrativo. Pamplona: Universidad de Navarra, 1998. 
habilitante que atribuye una potestad a la Administración, esta potestad ha de actuarse conforme a las exigencias de los principios.

Esta jurisprudencia tiene, en mi opinión, una proyección jurídica que va más allá de nuestras fronteras, puesto que perfila la función, el significado y la operatividad de los principios generales como elementos informadores del ordenamiento jurídico en general.

Si esto se analiza en sus justos términos, se comprenderá el alcance y significado de los principios generales como exponentes del ambiente general que ha de presidir el entero sistema normativo. Se trata, en este caso, de los principios como elementos basilares del ordenamiento, las columnas vertebrales que sostienen y dan vida a las normas jurídicas. Con palabras de la sentencia del Tribunal Supremo, son el oxígeno que envuelve a las normas, la atmósfera que permite su pervivencia. Si se desconocen o si se eliminan es como si dejara de existir el oxígeno para el hombre. Por eso los principios generales — desde esta perspectiva de elementos informadores y de criterios esenciales - han de ser tenidos muy en cuenta no solo por el intérprete de la norma, sino también por quien la elabora.

En materia de contratación pública, los principios son tan relevantes que ellos mismos sostienen todo el entramado normativo de la contratación, y ellos mismos aseguran que la regla esté presidida por los postulados del Estado de Derecho. Es decir, la objetividad, la transparencia, la igualdad de trata y la motivación de las adjudicaciones son materias que están disciplinadas por principios generales que han sido llevados al cuerpo de las principales normas que regulan la contratación pública a nivel global, tal y como tendremos ocasión de comentar en el siguiente epígrafe.

Es verdad que muchos principios han venido al mundo jurídico como consecuencia del trabajo de la doctrina y la jurisprudencia. Esto se comprueba estudiando el Derecho administrativo norteamericano y el Derecho administrativo comunitario europeo — este último especialmente en materia de contratos públicos- - En otros casos, además, los principios aparecen reflejados en las normas. Pero lo más importante es que existen por sí mismos, ya que son la proyección de la esencial idea de justicia en la realidad jurídica, aquella que trasciende al ordenamiento y le da sentido. Desde este punto de vista, los principios son previos al ordenamiento. Podría decirse que son su fundamento y que el ordenamiento se justifica en la medida en que dichos principios inspiran y presiden el sistema normativo. En el caso de la contratación pública global, esta afirmación es, sencillamente, exacta.

Pienso que esta idea gráfica sobre los principios como la atmósfera y el oxígeno de las normas explica hasta qué punto el olvido de los principios precipita la degradación del Derecho. Sin ser demasiado 
pesimista — más bien realista — podemos afirmar que frente al intento sistemático y pertinaz de convertir el Derecho administrativo en un mero apéndice del poder, los principios generales se levantan como valladar inexpugnable que permite evitar esta terrible operación. Antes bien, el Derecho administrativo del Estado de Derecho debe mucho a los principios generales. Tanto que si no fuera por ellos, probablemente la lucha contra las inmunidades del poder de la que habla García de Enterría hubiera sido desigual y con un claro vencedor. La exigencia de objetividad y transparencia en las contrataciones públicas - también en la dimensión mundial — facilita enormemente el control judicial de las adjudicaciones que los poderes de este tipo llevan a cabo todos los días.

Si pensamos en la contratación pública y en el progresivo vaciamiento del principio de igualdad de trato en el espacio jurídico europeo, comprenderemos hasta qué punto el desconocimiento de los principios generales en materia de contratación pública termina por desnaturalizar el sentido y significado de una categoría jurídica que - aplicada al Derecho administrativo- se justifica en la medida en que pone a disposición de la población obras y servicios en las mejores condiciones técnicas posibles que permiten el progreso y el desarrollo del país en tanto mejoran las condiciones de vida de los ciudadanos.

Conviene llamar la atención acerca de que el Tribunal Supremo Espanol, cuando ha construido la teoría del control de la discrecionalidad administrativa a través de los principios generales, ha conectado la existencia de dichos controles al genio expansivo del Estado de Derecho (sentencia del 8 de octubre de 1990). Efectivamente, el Estado de Derecho es un Estado de justicia, un Estado donde el poder ha de actuar conforme a patrones y cánones formales y sustanciales. Si nos quedamos únicamente en la vertiente procedimental y formal del poder, resulta evidente que esta puede ser la principal y más efectiva terminal del autoritarismo y ausencia de medida. Por eso, la existencia de controles sustanciales viene determinada por los principios que son, como vuelve a recordar esta sentencia, la atmósfera en que se desarrolla la vida jurídica, el oxígeno que respiran las normas.

En efecto, en materia de contratación, estos principios permiten a los tribunales de justicia enjuiciar las actuaciones de los entes públicos en la materia, al asegurar que las licitaciones se han realizado de acuerdo con los mínimos exigibles por el Estado de Derecho para la contratación pública: objetividad, imparcialidad, publicidad, concurrencia, igualdad de trato, etcétera.

Hoy en día, la mayor parte de los principios generales del Derecho están recogidos en las normas escritas. En materia de contratación pública global — como se comprobará en el siguiente epígrafe-, los principios generales han sido recogidos en las normas que regulan el campo. 
Durante largo tiempo, estos principios fueron construidos y levantados gracias al trabajo de la jurisprudencia y de la doctrina científica. Posteriormente pasaron a las normas hasta que, ya el día de hoy, estos principios generales del Derecho en materia de contratación pública global están explícitamente reconocidos dentro de las principales normas que regulan los más relevantes sectores del quehacer de los entes públicos.

A la fecha, la consideración del buen gobierno y de la buena administración de los asuntos públicos es desde luego otro elemento principial del Derecho administrativo global. En la Declaración del Milenio de las Naciones Unidas, así como en los más destacados documentos de reforma del Estado de casi todos los países, o a veces incluso en el marco de leyes y normas administrativas, el derecho a la buena administración y al buen gobierno es de los ciudadanos. Como es lógico, en materia de contratación pública también es de aplicación este principio de la buena administración.

En efecto, la consideración central del ciudadano en las modernas construcciones del Derecho administrativo y la administración pública proporciona el argumento medular para comprender en su cabal sentido este nuevo derecho fundamental a la buena administración. Se trata de un concepto señalado en el proyecto de la Constitución Europea (artículo II-101) y que está de acuerdo con el artículo 41 de la Carta Europea de los derechos fundamentales. La persona, el ciudadano, el administrado o particular, según la terminología jurídico administrativa al uso, ha dejado de ser un sujeto inerte, inerme e indefenso frente a un poder que intenta controlarlo, que le decía lo que era bueno o malo para él, al que estaba sometido y que infundía, gracias a sus fenomenales privilegios y prerrogativas, una suerte de amedrentamiento y temor que terminó por ponerlo de rodillas ante la todopoderosa maquinaria de poder en que se constituyó tantas veces el Estado. Hoy asistimos, a pesar de los pesares, al intento de la tecno-estructura global de considerar al ciudadano - no formalmente por supuesto- como un nuevo súbdito, cuando no un esclavo o una cosa susceptible de usar y tirar.

En materia de contratación pública, no debemos perder de vista que las obras o servicios públicos sujetos a las licitaciones han de ser realizados de la mejor manera posible, técnica y económicamente. Y esto, precisamente, porque los fondos públicos que van a financiar dichas actividades son de su propiedad. Por ello, lógicamente, tienen derecho a recibir obras y servicios de interés general, que permitan unas mejores condiciones de vida para todos. Afortunadamente, esta dimensión de la actividad pública se encuentra en el centro de la discusión sobre el alcance y el significado del quehacer de la administración pública en el Estado social y democrático de Derecho. 
El artículo 41 de la carta constituye un precipitado de diferentes derechos ciudadanos que a lo largo del tiempo y de los diferentes ordenamientos han caracterizado la posición central que hoy tiene la ciudadanía en todo lo que se refiere al Derecho administrativo. En el siglo XXI, el poder ya no mueve a su antojo al ciudadano, sino que este participa en la determinación del interés general; ya no define unilateralmente la administración pública. El ciudadano es más consciente de que el aparato público no es de la propiedad de los partidos, de los políticos o de los propios servidores públicos.

El derecho a la buena administración es un derecho fundamental de todo ciudadano comunitario a que las resoluciones que dicten las instituciones europeas sean imparciales, equitativas y razonables en cuanto al fondo y al momento en que se produzcan. Dicho derecho, según el citado artículo 41, incorpora a su vez cuatro derechos. Ahora, sin embargo, nos interesa solo subrayar que este derecho fundamental a la buena administración exige de las autoridades públicas que se conduzcan de acuerdo con equidad, imparcialidad y en tiempos razonables. Es decir, los principios de transparencia, imparcialidad, motivación, racionalidad e igualdad de trato están integrados también en la obligación de una buena administración.

Es más: de alguna manera puede decirse que el repertorio de principios del Derecho administrativo global parte de esta capital consideración por una razón fundamental: las exigencias de transparencia, racionalidad, motivación, objetividad, responsabilidad, participación o pluralismo que deben caracterizar a la acción de la administración global se deducen de este derecho del ciudadano, al ser este el dueño de las instituciones públicas.

En materia de contratos públicos, como ahora vamos a examinar, los principios han presidido las normas que diferentes entes públicos globales han ido elaborando. De hecho, puede decirse que es la materia de contratos públicos la que mejor ayuda a comprender el sentido principial que tiene el Derecho administrativo global.

\section{LOS PRINCIPIOS GENERALES DE LA CONTRATACIÓN PÚBLICA EN EL DERECHO ADMINISTRATIVO GLOBAL}

Si hubiera que elegir un sector concreto del Derecho administrativo global para explicar el sentido de los principios generales en su conformación, ese sector bien podría ser el de la contratación administrativa. Por muchas razones, pero sobre todo porque se puede afirmar sin riesgo que en esta materia los principios generales ya mencionados han sido los que han hecho posible la elaboración de normas relativas a las compras 
públicas, a través de las cuales se ha instaurado un verdadero Derecho administrativo global de la contratación pública.

En efecto, la existencia de la contratación pública en los espacios supranacionales debe su razón de ser a la relevancia de los principios generales de la contratación pública. En efecto, la contratación pública no adquiere carta de naturaleza normativa multilateral o global en el seno de los intercambios comerciales de la OMC hasta el 15 de abril de 1994 en Marrakech, cuando, en el seno de esta organización internacional de comercio, se firma el acuerdo sobre contratación pública que hace hincapié en la necesidad de evitar la discriminación en ella. Al mismo tiempo, este convenio constituye el corolario de la proyección del principio de igualdad de trato en los contratos que se realicen entre el sector público y las empresas de los diferentes países en lo que a realización de obras y servicios públicos de relevancia se refiere. El pacto mencionado figura en el anexo 4 del Acuerdo de Marrakech y obliga a los países que lo rubricaron.

Este acuerdo contiene los más fundamentales principios generales de la contratación pública que pasan del nivel interno al plano supranacional:

- el principio de trato no menos favorable que el otorgado a productos, servicios y proveedores nacionales;

- el principio de licitación pública con selección competitiva de los contratistas como regla con algunas excepciones para procedimientos restringidos en función de la naturaleza del contrato, principio de imparcialidad, principio de equidad, principio de transparencia;

- el principio de la cláusula de progreso científico o tecnológico, etcétera.

Es decir, se incorpora al Derecho administrativo global el conjunto de principios que rigen y han regido desde hace tiempo el ámbito de la contratación pública nacional.

El problema de este acuerdo — que fuera actualizado en 2006- es, como dice el profesor Moreno Molina ${ }^{2}$, que se aplica a un concreto y limitado número de países de gran relevancia comercial y se establecen obligaciones demasiado débiles como para que se pueda llevar completamente a la práctica. Además, la previsión en 2006 de la resolución de conflictos a través de arbitrajes pone de manifiesto hasta qué punto es necesario un tribunal administrativo global de contratación pública, integrado por personas expertas en la materia en las que concurran las

2 Moreno Molina, José Antonio y Francisco Pleite Guadamillas. La nueva Ley de contratos del sector público. Estudio sistemático. Madrid: La Ley, 2010. 
condiciones de imparcialidad y objetividad. El acuerdo es de aplicación en la UE a partir de la decisión del consejo 94/800 y forma parte del Derecho comunitario europeo.

En el marco de las Naciones Unidas debemos citar la llamada Ley Modelo sobre Contratación Pública en Materia de Bienes, Obras y Servicios. Se trata de un texto que se aprobó en 1993, que está en constante revisión y actualización, y que fue elaborado en el seno de la Comisión de Naciones Unidas para el Derecho Mercantil Internacional. La influencia de las directivas de la UE en materia de contratación es obvia: en realidad, este texto está diseñado como modelo en el que puedan inspirarse los países que no dispongan de regulación en materia de contratación pública o, en su caso, para actuar como derecho supletorio. Es evidente que los principios están muy presentes en este modelo, especialmente los de transparencia, objetividad y equidad.

Dentro de las normas sobre compras del sector público del Tratado de Libre Comercio de América del Norte, encontramos como principios fundamentales los de trato o no discriminación. En el seno del área de libre comercio de las Américas, el grupo de trabajo sobre compras del sector público está trabajando en un borrador de reglas que partan de los principios básicos de la contratación pública. Igualmente el Protocolo sobre Contrataciones Públicas de Mercosur parte del principio de igualdad de trato en materia de bienes y servicios.

Sin embargo, es en el marco de la UE donde esta cuestión está mejor regulada y articulada. Probablemente porque — como señala Moreno Molina-el espaciojurídico europeo es elámbitoterritorial supranacional en el que más y mejor se están armonizando los ordenamientos jurídicos de los estados miembros de la UE. Los derechos internos en la materia no presentan grandes diferencias. Además, la apertura al mercado de la contratación pública — exigencia de la esencia del sistema del Derecho comunitario europeo- obliga a diseñar unas normas muy exigentes en lo que se refiere a la participación de contratistas en las licitaciones que el sector público de cada país convoca para la realización de obras o servicios de interés general. El problema, que no es menor, estriba en que no es fácil ni sencillo que los Estados miembros dejen sin contratar a las empresas nacionales; así se generan efectos de proteccionismo y nacionalización, que en esta materia echan tantas veces por tierra los principios de igualdad y no discriminación, así como los de transparencia y objetividad.

Las razones que se aducen para justificar estas prácticas nacionalistas o proteccionistas, como señala Moreno Molina, son de diverso tipo. Se argumenta, por ejemplo, que por su envergadura, la contratación pública es una derivación de la política económica nacional; que a través de ella se puede intervenir en la vida política, económica y

LOS PRINCIPIOS DEL DERECHO GLOBAL DE LA CONTRATACIÓN PÚBLICA

THE PRINCIPLES OF GLOBAL PROCUREMENT 
social de los diferentes países; que se puede ayudar a la reconversión industrial en determinados sectores; que es un instrumento de apoyo al empleo en industrias en crisis; que afecta el prestigio nacional, etcétera. En realidad, contemplamos en la cotidianeidad que el principio de igualdad de trato cede en numerosas ocasiones por estas y otras argumentaciones. En ocasiones, incluso, nos encontramos - como señala nuevamente Moreno Molina— con prácticas difíciles de imaginar en un mercado que se califica de competitivo, tales como el reparto de mercados tácitos.

En los acuerdos y tratados firmados por la UE con otros países, nos hallamos también en presencia de principios. El acuerdo entre la UE y Chile de 2002 tiene un título dedicado a las compras públicas. En él ocupan un lugar muy destacado los principios de transparencia, racionalidad, no discriminación, igualdad de trato, competitividad abierta y efectiva, entre otros. Asimismo, el Tratado de Libre Comercio entre la UE y México de 2000 reconoce, en el apartado correspondiente a las compras públicas, el principio de trato nacional y de no discriminación. Cabe señalar que la UE tiene acuerdos comerciales, de asociación y cooperación con países vecinos y con países de Asia que igualmente incorporan los principios básicos de la contratación pública europea.

Es verdad que en el Tratado de la Comunidad Europea no hay preceptos específicos en materia de contratación pública, pero la razón es sencilla: en 1950 la contratación pública era una actividad poco relevante. Además, en esta materia y en el seno de la UE nos encontramos con dos tradiciones jurídicas bien distintas y dispares que dificultaban una solución unitaria. Mientras que en los países del régimen de Derecho administrativo francés la doctrina del contrato administrativo inspiraba los derechos en la materia, en el mundo anglosajón los contratos celebrados por las autoridades públicas eran simples contratos civiles regulados por el Derecho privado, como toda la actividad administrativa que en el Reino Unido no es más que una persona jurídica privada especial — pero a fin de cuentas, una persona jurídico privada-.

En reformas posteriores se incluyó un artículo 163 por el cual se decidió apoyar los esfuerzos de cooperación de las empresas; ello les permitía la plena utilización del mercado interior de la UE, en particular por medio de la apertura de la contratación pública. Es, pues, el mercado interior el que ha permitido la existencia de un acercamiento y una armonización de los derechos internos en la materia, como consecuencia de las directivas de la UE que han consagrado una serie de principios comunes al espacio jurídico administrativo europeo, de aplicación tanto a los países de tradición jurídica anglosajona como francesa.

Como señala Moreno Molina, se trata de principios que han cumplido $-\mathrm{y}$ cumplen - el papel de imprescindible elemento configurador del 
Derecho europeo de los contratos públicos. En Europa, pues, puede decirse que los principios son la razón de ser del Derecho administrativo de la contratación pública.

En este ámbito de la contratación pública, los principios generales de aplicación facilitan que en el sector exista un ambiente de seguridad y certeza jurídica en materia de aplicación e interpretación, que ayuda a que los fondos públicos que se destinan a obras y servicios públicos o de interés general —en la UE y en cada uno de los Estados miembroscumplan la finalidad que tienen asignada. Afirma Moreno Molina que estos principios parten de reglas alojadas en el Tratado de la CE y en el actual proyecto de Tratado Internacional por el que se instituye una constitución para Europa. Estos principios, hoy recogidos expresamente en las directivas que regulan esta materia, son el fundamento de todo el Derecho administrativo de los contratos públicos.

El propio Tribunal de Justicia de la UE, el órgano público que más ha contribuido a reforzar la relevancia de los principios en materia de contratación pública, señala que los principios de objetividad, imparcialidad y no discriminación en la adjudicación de los contratos públicos se extienden no solo a los contratos sobre los que recaen las directivas en la materia. Esta afirmación trae causa del carácter ciertamente fragmentario de las directivas en lo referido a contratación pública, pues estas no son regulaciones completas y acabadas sobre contratación pública. Por tal motivo, el TJCE, que es consciente de que los Estados miembros son libres para mantener o adoptar normas sustantivas o procedimentales que disciplinen los contratos públicos, afirma que tal disponibilidad normativa de los estados es comunitaria "a condición de que se respeten todas las disposiciones aplicables del Derecho Comunitario y, en particular, las prohibiciones derivadas de los principios consagrados por el Tratado" (sentencia CEI y Bellini del 9 de julio de 1987).

Esta doctrina es plenamente congruente con la propia naturaleza del Derecho comunitario, que tiene carácter preferente y es de aplicación directa en los Estados. De ello se deriva, como corolario necesario, que los principios que se encuentran ínsitos en las disposiciones del tratado son de general aplicación en los ordenamientos jurídicos internos de los diferentes Estados miembros de la UE. Una cosa es que las directivas hayan tenido que regular determinados sectores y determinadas materias y otra, muy distinta, que los principios generales no se apliquen a los supuestos no contemplados o estén excluidos de las directivas.

El Derecho comunitario es un derecho que se está confeccionado en el tiempo y que no se encuentra acabado. Los principios del tratado, sin embargo, tienen una vocación de proyección permanente sobre las normas que lo concretan, por lo que este ordenamiento —que en cada momento tiene el grado de evolución y de delimitación material que es

LOS PRINCIPIOS DEL DERECHO GLOBAL DE LA CONTRATACIÓN PÚBLICA

THE PRINCIPLES OF GLOBAL PROCUREMENT 
posible- está constantemente iluminado por la luz de los principios, que ayudan a comprender el alcance y sentido de las distintas instituciones y categorías que vertebran el Derecho administrativo europeo. En este sentido, la sentencia del TJCE del 3 de octubre de 2005 (Parking Brixen GMBH) dispone que:

[...] pese a que en el estado actual del Derecho Comunitario, los contratos de concesión de servicios públicos se encuentran excluidos del ámbito de aplicación de la Directiva 92/50, las Autoridades públicas que los celebren están obligadas no obstante a respetar, en general, las normas fundamentales del Tratado CE y, en especial, el principio de no discriminación por razón de nacionalidad.

En esta sentencia del 3 de octubre de 2005, como señala Moreno Molina en su obra colectiva, encontramos los fundamentos jurídicos que permiten comprender el alcance que tiene el principio de no discriminación en el Derecho comunitario europeo. Por una parte, el TJCE recuerda que el artículo 12 del tratado proclama la prohibición de toda discriminación por razón de nacionalidad, que el artículo 43 prohíbe las restricciones a la libertad de establecimiento de los nacionales de un Estado miembro en el territorio de otro Estado miembro y que el artículo 49 prohíbe las restricciones a la libre prestación de servicios dentro de la comunidad para los nacionales de los Estados miembros establecidos en un país de la comunidad, hoy de la UE, que no sea el del destinatario de la prestación.

Efectivamente, en estos preceptos del tratado se formula categóricamente el principio de no discriminación por razón de nacionalidad. Un principio que tiene diferentes posibilidades y que, en todo caso, se extiende a todas las relaciones jurídicas que se produzcan entre nacionales de un Estado miembro y otro Estado miembro y viceversa, como es obvio.

El TJCE ha señalado, en sentencia del 5 de diciembre de 1989 (ComisiónItalia), que los artículos 43 y 49 del tratado son una expresión particular del principio de igualdad de trato, como también es manifestación de este principio la prohibición de discriminación por razón de nacionalidad, tal y como ha precisado este tribunal por sentencia del 8 de octubre de 1980 (Uberschar).

La sentencia del TJCE del 3 de octubre de 1985 ha precisado, en esta dirección, que el principio de igualdad de trato de los licitadores, en la jurisprudencia relativa a las directivas comunitarias en materia de contratación pública, tiene por objeto que todos ellos dispongan de las mismas oportunidades al formular el contenido de sus ofertas, independientemente de su nacionalidad. Se comprende que este principio, conectado al de libertad de establecimiento, implique, en cuanto igualdad de trato y prohibición de la discriminación por razón 
de nacionalidad, que — como sigue diciendo esta sentencia del TJCEen esta materia de la contratación pública exista una obligación de transparencia que permita que la autoridad pública concedente se asegure de que los mencionados principios sean respetados. Es más, como sigue razonando esta resolución del TJCE, "esta obligación de transparencia que rehace sobre dicha autoridad consiste en garantizar, en beneficio de todo licitador potencial, una publicidad adecuada que permita abrir a la competencia la concesión de servicios y controlar la imparcialidad de los procedimientos de adjudicación".

En esta sentencia nos encontramos, pues, con todos los principios generales de la contratación pública: publicidad, concurrencia, objetividad, transparencia, imparcialidad, igualdad de trato, prohibición de discriminación por razón de nacionalidad, etcétera. En realidad, el mandato del artículo 163 de abrir la contratación pública al mercado, algo que era una consecuencia lógica de los principios del tratado, ha traído consigo la construcción de una serie de principios que, congruentes con el espíritu de la UE, traen causa — como ya señalamos- del propio ordenamiento jurídico interno de muchos de los países de la UE que entendieron que el régimen de Derecho administrativo de la contratación pública no podía llevar a un sistema cerrado de pétreos privilegios de una administración adjudicadora que cercenara la publicidad y la libre concurrencia en unos casos y que, en otros, fuese un sistema coherente con la competencia y el mercado abierto. Ahora la competencia, la libertad de establecimiento y la eliminación del monopolio han supuesto que en la contratación pública en la UE los países de tradición continental europea y los países de tradición anglosajona hayan de convivir con un régimen jurídico en el cual, al existir competencia, existe también — como criterio central — un entendimiento del interés público más abierto y dinámico.

El principio de licitación y de adjudicación en un proceso abierto y competitivo en materia de contratación pública ha sido también reconocido en la sentencia de 2005 que ahora estoy glosando. La licitación es, además, consecuencia — dice el TJCE— de otro precepto del tratado, el 86, que establece que los Estados miembros no adoptarán ni mantendrán, respecto de las empresas públicas y aquellas empresas a las que concedan derechos especiales o exclusivos, ninguna medida contraria a las normas del presente tratado.

El Derecho de los contratos públicos en los países de la UE obedece a principios y patrones comunes, que han sido alumbrados en el Tratado CE a partir de la idea central de la competencia, de los principios de igualdad y del libre establecimiento. Como consecuencia de la conformación de un mercado interior en él, las reglas sobre un sector de tanta trascendencia económica —como la contratación pública— ha 
de seguir unos criterios uniformes. Esta realidad ha sido posible gracias a la aprobación de un conjunto de directivas que han promovido la aplicación de los principios en todos los Estados miembros.

Insisto: el esfuerzo para someterse a estos principios por parte de los países de contrato administrativo y de los países de contrato civil demuestra hasta qué punto es posible una tarea de síntesis como la realizada en materia de servicios públicos y de interés general de ambas tradiciones jurídicas, al incorporar lo mejor y más razonable de cada uno de los sistemas jurídicos en el marco de los principios que han de presidir la materia de la contratación pública en Europa: transparencia, no discriminación y objetividad. En este sentido, por ejemplo, la directiva 2004/18/CE en el artículo 2 y la directiva 2004/17/CE en su artículo 10 son bien claras.

Tal y como ha señalado Moreno Molina, los principios que están en la base del Derecho comunitario de la contratación pública parten del los propios principios del Derecho originario establecido en el tratado. A saber: la prohibición de toda discriminación por razón de nacionalidad, el principio de libre circulación de mercancías, el principio de libre establecimiento y de servicios, y las normas sobre competencia.

En el marco de estos principios, se entiende el concreto régimen jurídico diseñado por las directivas para la contratación pública en la UE, con las modulaciones efectuadas por la propia jurisprudencia del TJCE, que ha precisado que estos principios son de general aplicación, aun cuando estemos en sectores excluidos del ámbito de aplicación de estas normas comunitarias. Así, por ejemplo, la sentencia del 22 de septiembre de 1988, tras afirmar la exclusión de la directiva de un determinado contrato, señaló a continuación que el principio de libre circulación de mercancías del artículo 28 del tratado es de general observancia. En el mismo sentido, pero ahora en relación con los principios de establecimiento y libre prestación de servicios, el TJCE, en sentencia del 5 de diciembre de 1989, entendió que tales principios del Derecho originario deben cumplirse en todo caso aunque estemos en un caso de un contrato excluido del ámbito de las directivas comunitarias.

La jurisprudencia del TJCE hace, además, que las directivas en la materia se interpreten conforme con los principios del tratado. Así, por ejemplo, la sentencia de 12 de marzo de 1990 ha sentado que no se puede interpretar estas directivas de acuerdo con una ley nacional contraria a los principios del tratado. Es más, el principio de prohibición de toda discriminación, a pesar de su escasa virtualidad operativa en la realidad, es considerado por el TJCE como el fundamento de todo el sistema de contratación pública a nivel comunitario, tal y como ha establecido la sentencia del 22 de junio de 1993. 
Este principio es una manifestación de la igualdad de trato, que según la sentencia del 14 de diciembre de 2004, reclama que no se traten de forma diferente situaciones que son comparables, y que situaciones distintas no sean tratadas de manera idéntica, salvo que ese trato esté justificado objetivamente. Es calificado de fundamental por el propio TJCE, en cuya virtud (sentencia del 13 de julio de 1993) "se prohíben las discriminaciones manifiestas basadas en la nacionalidad [...], sino también cualquier otra forma encubierta de discriminación que, aplicando otros criterios de distinción, conduzca de hecho al mismo resultado".

El principio de igualdad de trato impide, según el TJCE, que el poder adjudicador tenga en cuenta una modificación realizada por un licitador, porque tal situación provocaría una situación de ventaja para uno de los oferentes; se rompería así el principio que, como también ha precisado la jurisprudencia comunitaria, está unido al de transparencia, pues no es posible autorizar que los competidores dispongan de distintas condiciones a la hora de presentar sus ofertas, tal y como ha señalado la sentencia del 25 de abril de 1996.

Resulta interesante subrayar que en esta materia la jurisprudencia ha señalado que la gestión diligente del proceso de contratación pública es exigencia de los principios de buena administración y de igualdad de trato (sentencia del 29 de abril de 2004). Principio de buena administración, al que hicimos referencia en el anterior epígrafe, que es considerado - tras la Carta Europea de los Derechos Fundamentalestambién como principio de obligatorio cumplimiento para los poderes adjudicadores en el marco de la gestión del proceso de la contratación administrativa. En este sentido, merece la pena destacar que el propio defensor del pueblo de la UE, en virtud del principio de la buena administración, destacó en su decisión del 22 de abril de 2002 que, según las buenas prácticas administrativas, en los procedimientos de licitación la administración debe atenerse a las normas establecidas para tales procedimientos. Estas normas están presididas, como bien sabemos, por los principios generales de la contratación pública que se derivan a su vez de los principios de Derecho originario señalados en este epígrafe.

Estos principios, que son corolario necesario del principio de competencia y de igualdad de trato, suponen una evidente limitación a una interpretación expansiva de lo que en el Derecho de los contratos administrativos son los privilegios o prerrogativas de la administración. Ahora bien, estos principios modulan de tal manera el ejercicio de estas potestades que bien puede decirse que no serán congruentes con el Derecho comunitario europeo cuando impliquen una quiebra de los ya citados principios. Dicha quiebra no será tal cuando se produzca una desigualdad justificada objetivamente, lo que solo puede acontecer cuando tal situación se ampare en razones de interés general, convenientemente 
argumentadas en el caso concreto por el poder adjudicador. De esta manera, el entendimiento de los tradicionales poderes extraordinarios de la administración en materia de contratos administrativos, potestas variandi, rescisión unilateral o interpretación unilateral ha de hacerse en el marco de los principios generales que se derivan del Tratado CE.

En tal sentido, por ejemplo, la sentencia del 25 de abril de 1996 ha entendido que la atribución a la entidad adjudicataria de una libertad incondicional de elección no es conforme al Derecho comunitario. Se prohíbe la arbitrariedad, que es, como diría Locke, la ausencia de racionalidad. Así — como sigue diciendo la sentencia-, la mera circunstancia de que un criterio de adjudicación verse sobre un dato que se conocerá con precisión después de la adjudicación del contrato no puede interpretarse en el sentido de que confiere libertad incondicional a la entidad en cuestión.

También el principio de libre circulación de mercancías es de aplicación a la contratación pública en la dimensión comunitaria, puesto que — como señala atinadamente Moreno Molina- es el título que justifica la intervención comunitaria en la materia. Igualmente, el derecho de establecimiento y a la libre prestación de servicios son principios que permiten la eliminación de discriminaciones, tanto por razón de nacionalidad, como por cualquier otra razón —encubierta o no- que traiga consigo la quiebra del principio de igualdad de trato.

En fin, los principios de la contratación pública en el espacio jurídico europeo surgen de la propia irradiación de la luz de los principios fundamentales del tratado sobre una realidad hasta no hace mucho tiempo considerada irrelevante, pero que hoy en día tiene una importancia trascendental también para el desarrollo económico y la cohesión social de los países y de los entes supranacionales. Si tenemos en cuenta la sentencia del 17 de noviembre de 1993 del TJCE, los principios examinados traen causa de la realización del mercado interior basado en libertad de establecimiento y libre prestación de servicios, así como de la necesidad de garantizar la efectividad de los derechos reconocidos por el tratado en materia de contratación pública, que son los de competencia, publicidad, igualdad de trato y prohibición de discriminación, objetividad, imparcialidad y transparencia.

\section{IV.REFLEXIÓN CONCLUSIVA}

El Derecho administrativo global es un Derecho in fieri, en formación, que no está sistematizado, que todavía no se ha estudiado con pretensiones sistémicas, aunque se admite su existencia al igual que se reconoce que la globalización también alcanza, —cómo no- al campo del Derecho administrativo. Los autores que en mi opinión más 
han estudiado el tema (Kingsbury, Krisch y Stewart) y cuyo estudio sobre la emergencia del Derecho administrativo global es uno de los materiales más relevantes sobre la materia son partidarios de ir con cautela. Se alinean más bien bajo un enfoque pragmático: observar lo que funciona y construir desde esa perspectiva. En el caso del Derecho de la contratación pública, se ha construido — gracias a la UE — todo un sector del Derecho administrativo global de contenido principial que, como vemos, se extiende por todo el mundo, ya que consiste en principios que se derivan, de forma general, de una experiencia de integración sellada por los compromisos del Estado de Derecho tal y como es la UE.

Al no existir una Constitución global ni tampoco poderes públicos a nivel global claramente definidos, el ordenamiento jurídico plantea algunas dificultades acerca del establecimiento de principios sobre los cuales levantar el edificio del Derecho administrativo global. En materia de contratación pública, pienso que el espacio jurídico administrativo de la UE puede considerarse como un ejemplo a seguir por las razones anteriormente expuestas.

Sin embargo, sobre la base de la Declaración Universal de los Derechos Humanos es más que posible - teniendo en cuenta la realidad de las normas, actos y resoluciones judiciales que se producen en este ámbito- establecer un catálogo de principios que, para quien escribe, deben partir de la cláusula del Estado de Derecho. Si somos fieles a lo que supuso la aparición del Derecho administrativo en Europa tras la caída del antiguo régimen, tenemos que ser conscientes de que hoy el régimen general requiere de nuevos impulsos jurídicos que restauren y recuperen el sentido del Derecho administrativo como un Derecho que lucha por reducir los poderes públicos y económicos a sus justos límites. Todo esto a través del principio de buena administración, en el cual se halla el sentido de sus principios inspiradores: racionalidad, participación, pluralismo, rendición de cuentas, transparencia, revisión, responsabilidad, entre otros. Ahí encontraremos un buen camino para la construcción de un orden jurídico-administrativo global que permita que el Derecho administrativo sea lo que debe ser: el Derecho del poder para la libertad.

Agustín Gordillo nos recuerda que son precisamente los principios de seguridad jurídica y de justicia aquellos que deben presidir esta nueva expresión de la tendencia permanente a la unidad del ordenamiento jurídico que hoy, para el caso del Derecho administrativo, denominamos "Derecho administrativo global". En ese sentido, si proyectamos ambos principios sobre la realidad económica, el principio de racionalidad - del que hemos tratado extensamente en estas líneas bajo la denominación de "objetividad" o "igualdad de trato con prohibición de 
discriminación" - se nos presenta como un elemento que es la misma proyección del más general principio de racionalidad derivado del Estado de Derecho al funcionamiento de la actividad económica. En ese ámbito, los contratos públicos juegan un papel importante.

A través de los postulados del pensamiento abierto, plural, dinámico y complementario, pienso que es más sencillo comprender el alcance del Derecho administrativo global de entre sus muchas versiones y aproximaciones, siempre que se tenga en cuenta su condición de garante y asegurador de los derechos de los ciudadanos. Si nos quedamos en un enfoque funcional que legitime los excesos y los abusos de una tecnoestructura que no aspira más que al dominio global a través del poder y la economía, entonces habremos perdido el tiempo. En tiempos en que el Derecho administrativo global está en pleno auge, en lugar de renunciar a establecer el solar sobre el que levantar este edificio, estas páginas pretenden contribuir al debate sobre la necesidad de que el Derecho administrativo global — como Derecho que es y por ello producto cultural - exprese un punto de vista sobre la justicia de base profundamente humanista, de manera que la libertad solidaria de los ciudadanos pueda ser garantizada también desde el orden jurídico administrativo global. En materia de contratos, como ha quedado expuesto, la libertad, la competencia, la igualdad de trato, la objetividad o la transparencia reclaman un Derecho que piense más en los ciudadanos y menos en los poderes de los entes públicos.

En materia de contratación pública, se trata de facilitar a los ciudadanos los servicios, suministros y obras públicas que repercutan positivamente en las condiciones de vida de los habitantes. Para ello, los tradicionales poderes de la administración en los países de contrato administrativo han de entenderse de otra manera: como poderes que pueden operarse cuando lo exija el interés general concreta y puntualmente argumentado. El Derecho administrativo de la UE ha traído — en materia de contratación pública - la idea de que en este campo, al manejarse fondos públicos, ha de buscarse siempre la empresa que esté en mejores condiciones de llevar a cabo la obra, prestar el servicio o el suministro de turno. 